\title{
Digital Shift in Swiss Media Consumption Practices
}

\author{
Maud Reveilhac* and Davide Morselli*
}

\begin{abstract}
Relying on the 2013 and 2016 rounds of individual questionnaires from the Swiss Household Panel (SHP), we use multiple correspondence analysis to map Swiss media consumption practices while making use of the longitudinal character of panel data in an innovative way. Our results show that individual practices can be distinguished along two main dimensions: on the one hand, the reliance on new media, which is explained mainly by the age cohort, and on the other hand, the consumption of news, which is explained mainly by changes in political interest as well as by gender.
\end{abstract}

Keywords: media consumption, social media, longitudinal perspective, MCA

\section{Changement des pratiques de consommation des médias en Suisse}

Résumé: À partir des données individuelles des éditions 2013 et 2016 du Panel Suisse des Ménages, nous dressons le portrait des pratiques de consommation médiatique suisse en recourant à l'analyse de correspondances multiples, tout en exploitant de manière innovante le caractère longitudinal des données panel. Nos résultats montrent que les pratiques individuelles comportent deux dimensions principales: $d$ 〉une part, le recours aux nouveaux médias, essentiellement lié aux cohortes d'âge; drautre part, la consommation d'informations, basée principalement sur lévolution de lintérêt politique, ainsi que le genre.

Mots-clés: consommation des médias, médias sociaux, perspective longitudinale, ACM

\section{Die digitale Veränderung der Schweizer Medienkonsumpraktiken}

Zusammenfassung: Basierend auf den Wellen 2013 und 2016 des Schweizer Haushaltspanels, verwenden wir eine Mehrfachkorrespondenzanalyse, um die Schweizer Medienkonsumpraktiken zu beleuchten, und gleichzeitig den Längsschnittcharakter der Paneldaten auf innovative Weise nutzen. Unsere Ergebnisse zeigen, dass sich die Medienkonsumpraktiken in zwei Hauptdimensionen unterteilen: Zum einen lässt sich die Nutzung von Neuen Medien hauptsächlich durch Alterskohorte und den Beschäftigungsstatus erklären. Zum anderen erklärt sich der Nachrichtenkonsum vor allem durch die Veränderung des politischen Interesses und durch Geschlecht.

Schlüsselwörter: Medienkonsum, Social Media, Längsschnittperspektive, MKA

University of Lausanne, Life Course and Inequality Research Centre (LINES), CH-1015 Lausanne, maud.reveilhac@unil.ch and davide.morselli@unil.ch. 


\section{Introduction}

In the spring of 2018, the oldest ad agency in Switzerland, Publicitas, collapsed within a span of a few weeks. It missed the digital shift, having been at the forefront of media until the turn of the year 2000. At the same time, the leading Swiss media company, Tamedia, deleted the printed version of one of its main daily newspapers, Le Matin, choosing to continue with only a digital version.

The news media are facing profound changes due to the development of digital technology, new competing media that are emerging, and the new individual media patterns that are developing (Willemin 2018). Current media usage is marked by the arrival of new media companies on the Internet and by the prominence of social networks, and Switzerland is no exception. Both media technology and the very essence of news content and consumption are changing: while consumers are especially fond of free news and the dissemination of information is now immediate, online news is often obtained in a fast and superficial way (Flaxman et al. 2016; Eveland et al. 2004), and social media are becoming an important source of information, especially for young adults (Fög 2017).

This study aims to map the media digital shift in Switzerland by drawing from individual media consumption practices, focusing particularly on the relationship between social media and other media usages. More precisely, we focus on two aspects. First, we are interested in detecting whether a digital shift has taken place in media use practices. In other words, can we account for a digital-oriented versus a paper-oriented media consumption space? Second, we aim to explore what individual factors can explain the formation of this new media space and discuss whether the generational divide can be supplemented by another divide related to news skills.

The present study makes use of longitudinal data from the Swiss Household Panel (SHP) and relies on a dynamic version of multiple correspondence analysis (MCA) to answer our research questions. The panel nature of the SHP data offers insights that are otherwise masked when researchers rely on population aggregates because it allows us to track changes in consumption patterns. We thus adopt a data-mining approach to investigate media consumption changes among SHP respondents.

In the next section, we begin with an overview of the state of knowledge about media consumption in Switzerland. Then, we describe the main sources of data and present our method of analysis. In addition to providing substantive findings on the mapping of the Swiss media consumption patterns, this study suggests an innovative and dynamic use of MCA that has remained marginal in social sciences practices until now.

\subsection{Changing media in a changing society}

The societal role of mass media has been studied broadly, especially in relation to public opinion and political propaganda (Kaene 1991; Hart 1999; Street 2005). 
In the last few decades, a constructionist approach to the study of public opinion (Bennett 1993; Gamson and Modigliani 1989; Kertzer 2001; Neisser 1976; Price 1988) has moved away from considering media as a mere cause of opinion formation. These studies have moved in the direction of a more complex model in which people and media actors interact and co-create opinions and cultural and political value. According to this approach, the meaning of a particular phenomenon is constructed in the interaction between actors. In the case of media they should not be considered empty vessels to be filled with information; they are actors in interaction with another actor: the media (Ball-Rokeach and DeFleur 1976). This approach to the analysis of media becomes even more relevant when looking at the rising importance of online media, in which actors are often in direct contact, instead of only cognitive exchange. For instance, social media allow people to exchange near-to-real-time information, transmitting news and user-generated content to each other. Similarly, journalists have increased their presence on social media to interact with readers, promote their articles (Hedman and Djerf-Pierre 2013), and gather publishable information (Alejandro 2010).

If the diffusion of new media has often been welcomed as a grassroots process for generating public opinion and making information more democratic, in reality, it goes hand in hand with several aspects that are worthy of concern. First, the cognitive processing of online news is fairly different for different categories of users. Some psychological research has shown that whereas experienced Internet users benefit from the online structure of news, expert users show a drop in attention and information processing (Opgenhaffen and d'Haenens 2011; Tran 2015). Web-based media might indeed facilitate a cognitive overload, which, in turn, is negatively related to information comprehension (Hou and Wang 2016). In other words, online media may make the reader process too much information, compromising the comprehension of its content and resulting in a superficial understanding of news.

Online media have been under the spotlight not only for comprehension but also for a series of side effects on the diffusion and formation of opinions. Some studies have shown that social media tend to increase the polarization of opinions by creating echo chambers, in which people are mostly exposed to opinions similar to their own via social media such as Facebook and Twitter (e.g., Quattrociocchi et al. 2016; Colleoni et al. 2014). This effect is amplified by the increasing use of personalized content by the major web corporations. Automated algorithms facilitate ideological segregation by offering only content from sources that fit the user's preferences and opinions and by creating filter bubbles in which users are rarely exposed to different opinions and viewpoints (Pariser 2011).

Against the expectations of more horizontal and democratic communication, the effects of algorithms on public opinion might be particularly problematic for the correct functioning of a democratic system. Democracy is rooted in the assumption that heterogeneous worldviews and opinions can coexist and counterbalance each 
other towards a common goal and reach optimal solutions. Echo chambers and filter bubbles can instead create the illusion where a person believes that everyone believes what he/she believes and that there are no other opinions. Similarly, people might get the impression that only a limited number of events are occurring because news feeds are filtered by algorithms that prompt only preferred (i. e., the most browsed) types of news and topics.

Social media have had an increasing role in political communication, and it has been strategically used by political elites to shift votes and create opinions (Ratkiewicz et al. 2011; see also Woolley 2016 for a review). Thus, we might wonder about the role of online media on direct democracy systems, in which the population is called to vote on various issues several times a year and receiving information on the pros and cons of each issue is pivotal for the functioning of the system. In direct democracy systems, public opinion polarisation and the side effects of online media, such echo chambers and filter bubbles, may have profound political consequences. The long-lasting tradition of direct democracy makes Switzerland a case worth monitoring in the context of a changing landscape and a progressive shift toward online news and social media as information sources.

\subsection{The media landscape in Switzerland}

In recent decades, the media landscape in Switzerland has been characterized by multilingual complexity, strong public broadcasting of radio and television programming, and a general trend of media concentration and the downsizing of journalism. Echoing the situation in many other European countries, political pressure on public broadcasting has increased. In Switzerland, right-wing politicians launched a popular initiative in 2017, known as No Billag, which aimed at abolishing the provision of public funds to the public news service altogether. It was heavily rejected by more than $70 \%$ of the electorate. Swiss citizens thus remain loyal to the quality journalism offered by public broadcasting, despite the trends encouraging them to rely ever more heavily on the Internet and social media for information.

Concerning reliance on the Internet, the Swiss section of the World Internet Project - a comparative survey conducted every year since 2011 on a representative sample of the Swiss population by the Institute of Mass Communication and Media Research (MCMR) at the University of Zurich - showed a clear pattern towards a digital shift for news consumption (Latzer 2017). The Internet was the most important source of media information in Switzerland in 2017, ahead of newspapers and television. It further showed that average Internet usage time has doubled since 2011 and currently stands at 25.5 hours a week, with young and poorly educated people spending the most time online. The number of non-users declined by half during the past six years, and the number of absolute non-users in Switzerland amounted to approximately $5 \%$ of the population. 
The 2017 edition of the Annales survey showed that $41 \%$ of the Swiss population received information mainly from news sites or through social media (Annales 2017). Concerning the reliance on social media as a source of journalism, the Digital News Report produced by Reuters in 2016 reported that 8\% of Swiss news consumers said that social media had become their main source of journalistic information (Reuters 2016), which is similar to trends founds in other European countries (Fög 2018). In 2018, the same report showed that one-third of the Swiss population cited Facebook as a source of news, while trust in news content on social media also remained low, at 22\% (Reuters 2018). The 2016 report on media quality in Switzerland showed a correlation between reading only free or lower-quality journalism sources, including social media, and trust in the media system (Fög 2016). Young people, however, remain over-represented among the users of social media platforms as a source of information (Fög 2017).

The increasing reliance on the Internet and on social media as a source of journalism does not necessarily imply that readership is becoming less informed and less interested in keeping up-to-date about the current state of affairs. However, it raises questions about the necessary skills to process a wide amount of available news to distinguish between good and bad information. On May 10, 2017, the Swiss Federal Council published a status report on the legal basis for social media acknowledging that the increased influence of false information on political discourse is currently a source of lively debate, as social media play a central role in spreading fake news (Swiss Federal Council 2017). The growing global debate on fake news (Gorodnichenko, Pham and Talavera 2018) is also reflected in the user behaviour captured in the abovementioned MCMR survey. In the information category, factchecking (78\%) and searching for news (86\%) have seen the most significant increases in the past few years. Until 2013, three-quarters of the Swiss population rated at least half of online content as trustworthy. This number dropped to 58\% in 2017.

\subsection{Two complementary hypotheses on media consumption patterns}

These studies show that the Swiss media consumption patterns have constantly changed in the past few years and that readers are increasingly turning to online media for quick information. In this context, the quality of media must adapt to new consumer behaviours, and news agencies must face new economic constraints due to the declining revenue for traditional media.

The consequences of this digital shift concern the entire population, and the notion of what constitutes the news might also be affected. As suggested by Genner (2017), in addition to a generational divide that is expressed in the form of a heavier reliance on social media as a source of journalism among younger people, there is also a divide in the skills to treat the information available. The generational divide hypothesis may therefore also be complemented, rather than opposed, by a skills gap hypothesis. In the long run, there might even be a replacement of the former trend 
by the later as technological skills become diffused in society. Furthermore, as the online setting might also amplify opinion polarisation, it is also likely that political factors will play an increased role in the choice of media consumption patterns.

Given the on-going digitisation of news, our main aim is to understand how media information works in relation to online news and to social media while illustrating shifting media usage with individual sociodemographic and political factors. Determining media use, education, socioeconomic status, political interest, and political orientation can be complementary explanatory factors to age. Furthermore, the living context, such as the residential area, may also be important factors. For instance, the pools of potential customers of news media are below the national average in mountain regions and rural areas, where the public (and to a lesser extent private) broadcasting plays a central role, while free newspapers are less important than they are in towns and agglomerations (Hauptli 2017).

\section{Data and method of analysis}

\subsection{Data}

The SHP offers unique panel data for Switzerland; it contains questions covering Swiss people's behaviours regarding social media and the broader use of the Internet. The SHP data provide information about individuals' political positioning and interests, as well as information on the occupational status and residential area, and they enable cohort analysis. We rely on wave 15 (2013) and wave 18 (2016) of the SHP questionnaire, which are the only available waves, including media consumptionrelated questions. We restricted our analysis to a subset of the sample that provided valid responses to a series of questions about individual media consumption in 2013. Our total sample consists of 1970 individuals.

The SHP questionnaire asked about the use of social media, and we recoded the data into three categories: Facebook and Twitter users, other social media users (including LinkedIn, Xing, MySpace and Google+), and people without any social media accounts. Although Facebook and Twitter may encompass different populations, we kept them in a single category to reach a sufficient number of people in each category. Then, we included variables accounting for three broad categories of Internet usage: frequency of chatting, frequency of reading news online and frequency of listening to the radio and watching TV on the Internet. The original scale was recoded into $1=$ frequent use ( which included $1=$ every day and $2=$ once to several times per week) and $0=$ rare use $(3=$ once to several times per month, $4=$ once to several times per year and $5=$ never). Similarly, variables related to paper media consumption were retained and recoded using the same procedure: frequency of reading daily offline newspapers, free offline newspapers, and magazines. 
To investigate political attitudes that could impact media consumption patterns, we used the SHP measures of political interest and self-positioning. The original scales ranged from 0 to 10 , and to measure the changes in political interest and self-positioning, we subtracted the values from 2016 to 2013, which results in a scale ranging from -9 to +9 . Concerning political interest, change was coded into seven categories: increased level of political interest (positive values from 2 to 9 from the subtraction); decreased level of political interest (positive values from -2 to -9 from the subtraction); no change ( 0 and \pm 1 from the subtraction) with medium levels (from 4 to 6 on the original scale); no change with very low levels (from 0 to 1 on the original scale); no change with low levels (from 2 to 3 on the original scale); no change with very high levels (from 9 to 10 on the original scale); no change with high levels (from 7 to 8 on the original scale).

A similar procedure was used to recode the change in political self-positioning into seven categories: change in political self-positioning to the right of the political spectrum (positive values from 5 to 9 from the subtraction); change to the left (negative values from -5 to -9 from the subtraction); no change ( 0 and \pm 1 from the subtraction) with a centre political self-positioning (from 4 to 6 on the original scale); no change at the moderate right (from 7 to 8 on the original scale); no change at the extreme-right (from 9 to 10 on the original scale); no change at the moderate left (from 2 to 3 on the original scale); and no change at the extreme-left (from 0 to 1 on the original scale).

Several demographic variables were also included in the analysis. We assigned each person to one of six birth cohorts: <1942, 1943-1952, 1953-1962, 1963-1972, 1973-1982, and 1983-1999. Moreover, we included education level in 2016 that we recoded into four categories (tertiary, compulsory, general, and vocational). We also included occupational status in the year 2016 recoded as active (originally full-time paid work (at least 37 hours weekly), and work in protected atelier (for handicapped persons), part-time paid work (5-36 hours weekly and part-time paid work (1-4 hours weekly)), and inactive (originally retired people and other retired persons, other situations, further education, non-paid leave and work in the family company). Residential areas were coded into centres, urban areas (including suburban municipalities, mixed agricultural municipalities and peripheral urban municipalities), wealthy municipalities, tourist municipalities, industrial and tertiary sector municipalities, and rural areas (including rural commuter municipalities and peripheral agricultural municipalities). Last but not least, we also included the 7 large regions of Switzerland (Zurich, Central Switzerland, East Switzerland, Lake Geneva, Middleland, Northwest Switzerland, and Ticino), and gender was controlled.

\subsection{Analytical strategy}

To map the Swiss media landscape on the basis of individual media consumption measures, we used MCA, which can be understood as a multivariate factor analysis 
for categorical variables. MCA is usually visually represented in two plots: the graph of active modalities that determine the shape of the obtained map and the graph of supplementary modalities that serve to interpret the map. The spatial proximity between two modalities indicates in these graphs that these modalities are shared by a relatively large group of individuals. As people share more common patterns, they become more closely situated in the plan. Compared to other types of analysis, MCA has the advantage of accounting for complex (i. e., non-linear) relationships between variables and variable modalities. For this reason, MCA is a powerful analytical approach to analyse social categories and to investigate numerical variables once transformed into categories.

MCA allows us to model oppositions between variables in the logic of axes (or factors). The total information taken into account by each axis (inertia) is given by the variance rate explained (in the form of percentages) and by the eigenvalue of each axis. These indicators are thus used to determine the number of axes (factors) to retain for the analysis. For interpretation, we generally retain the number of axes that, when their respective rates are added, represent at least $80 \%$ of the cumulative variance rate. The first axis, which includes the variables with the highest inertia, represents the most important opposition; the second axis, the second most important, and so on. To interpret the difference between two modalities, it is customary to consider a difference of 0.5 as significant and a difference of 1 as very significant (Rossier 2018).

As already mentioned, in MCA, variables can be analysed in two ways. First, a set of variables, named active variables, is used to define the axes and the distance between variables and between individuals. Once the space is formed by the oppositions between modalities of the active variables, it is possible to project additional (or illustrative) variables. Illustrative variables do not play any role in the formation of the axes.

Each active variable and each modality of an active variable contribute to a percentage of the inertia of each axis. By convention, active variables are considered as contributing to an axis when this percentage exceeds the average inertia contribution (100\% divided by the total number of variables). Similarly, we consider a modality as contributing to an axis when it exceeds the average contribution of modalities (100\% divided by the total number of modalities). To interpret the difference between two modalities, it is customary to consider a difference of 0.5 as significant and a difference of 1 as very significant (Rossier 2018).

Our model had 7 active variables and 30 active modalities, for a total of 1970 respondents. Active variables are considered important when their contribution to an axis is larger than $14.3 \%(=100 / 7)$. Similarly, the threshold of modalities is set at 3.3\% (=100/30). The details for our variables can be found in Appendix 1 .

Faithful to a longitudinal perspective, MCA analyses the media use of the same individuals at two time points, namely, 2013 and 2016. We modelled the 
active variables by focusing on the respondents' positions between 2013 and 2016 (as described in the data section). It is thus possible to observe whether and how changes in individual positions over time affect media consumption patterns. This dynamic use of MCA has - to date - rarely been applied in the social sciences.

The different media consumption types in 2013 and 2016 were inserted as active variables in the model to examine the structure and evolution of media consumption in Switzerland. Then, we superimpose, as illustrative variables, the positions of the individuals on several variables that could explain the mapping of the media space. Illustrative variables include the different age cohorts, the variation in political interest, the variation in political self-positioning, as well as the level of education in 2016, the occupational status in 2016, the living area, the 7 big regions, and gender.

\section{Results}

\subsection{Description of media usage}

Between 2013 and 2016, the use of social media has evolved, with alternatives to Facebook and Twitter becoming more popular. Table 1 reports the descriptive statistics for our sample. The percentage of respondents without any social media account was the highest (56\% in 2013 and 53\% in 2016), followed by respondents with either Facebook or Twitter accounts (39\% in 2013 and 40\% in 2016). Respondents relying on other social media platforms had slightly increased $5 \%$ in 2013 and $7 \%$ in 2016).

If we focus on the three main reasons for consulting the Internet, online news consumption was higher than chatting and listening to the radio or watching TV online, and the proportions had increased between the survey years (from $66 \%$ to $72 \%$ for news consumption, from $14 \%$ to $17 \%$ for chatting and from $21 \%$ to $25 \%$ for listening to the radio or watching TV online). Concerning paper media, the consumption of daily news had decreased (from $83 \%$ to $80 \%$ ), as had the consumption of magazines (from 54\% to 51\%). In contrast, the consumption remained the same for free news (54\%). Overall, there was almost no change in the proportions of media consumption between the two survey years.

Table 2 reports the correlation among the study variables. Online behaviours (reading news, chatting and listening to the radio or watching TV on the Internet) were all positively correlated with each other for both survey years. Social media use was negatively correlated with reading traditional offline media, such as newspapers and magazines. It was instead positively correlated with free news and online news consumption, as well as with chatting and listening to the radio or watching TV on the Internet. These patterns hold for both survey years. There is thus a correlation between using social media and reading only free or lower-quality sources. 
Table 1 Descriptive statistics for the active variables

\begin{tabular}{lcrrrrc}
\hline & Modalities & 2013 & count $(\%)$ & 2016 & count $(\%)$ & $p$ \\
\hline Social media (Socialmedia) & Facebook/Twitter & 763 & $(39)$ & 787 & $(40)$ & 0.450 \\
& Other & 1112 & $(56)$ & 1039 & $(53)$ & $0.021^{*}$ \\
& None & 95 & $(5)$ & 144 & $(7)$ & $0.001^{* *}$ \\
Chatting (chatting) & no & 1692 & $(86)$ & 1629 & $(83)$ & $0.006^{* *}$ \\
& yes & 278 & $(14)$ & 341 & $(17)$ & \\
Radio and TV (radio_TV) & no & 1550 & $(79)$ & 1471 & $(75)$ & $0.003^{* *}$ \\
& yes & 420 & $(21)$ & 499 & $(25)$ & \\
Onlinenews (onlinenews) & no & 677 & $(34)$ & 547 & $(28)$ & $<.000^{* *}$ \\
& yes & 1293 & $(66)$ & 1423 & $(72)$ & \\
Newspaper (newspaper) & no & 327 & $(17)$ & 407 & $(21)$ & $0.001^{* *}$ \\
& yes & 1643 & $(83)$ & 1563 & $(79)$ & \\
Freenews (freenews) & no & 907 & $(46)$ & 911 & $(46)$ & 0.923 \\
Magazines (magazines) & yes & 1063 & $(54)$ & 1059 & $(54)$ & \\
& no & 912 & $(46)$ & 968 & $(49)$ & $0.079^{\text {* }}$ \\
& yes & 1058 & $(54)$ & 1002 & $(51)$ & \\
\hline
\end{tabular}

Note: significance levels defined as ${ }^{* *} p<0.01,{ }^{*} p<0.05,{ }^{a} p<.08 ; N=1970$.

We further note that individuals who do not use social media also tend to avoid any online activities, such as reading news online, chatting, listening to radio or watching TV online. These persons also prefer reading newspapers instead of free news. These findings already indicate that a divide is taking place not only with respect to the use versus non-use of social media but also with regard to quality versus lowquality information consumption. Furthermore, the users of other types of social media, such as Facebook and Twitter, seem to follow a different logic because they tend to be actively involved in online practices but have no significant pattern related to offline news consumption.

\subsection{Description of individual variables}

Concerning the supplementary variables, the majority of respondents $(84 \%)$ did not express any change in their political self-positioning between 2013 and 2016: $47 \%$ remained at the centre of the political spectrum, $21 \%$ on the left, and $16 \%$ on the right. Approximately one-tenth of respondents expressed a shift towards the left $(9 \%)$ or the right $(7 \%)$ of the political spectrum. With respect to political interest, approximately one-tenth of respondents expressed either an increased (13\%) or decreased $(10 \%)$ interest in politics. A total of $9 \%$ of participants did not express any change in their level of political interest and remained uninterested in politics represent $9 \%$, while $46 \%$ remained interested in politics.

With respect to socio-demographic supplementary variables, the distribution of cohorts does not overrepresent the youngest age groups. Regarding occupational 


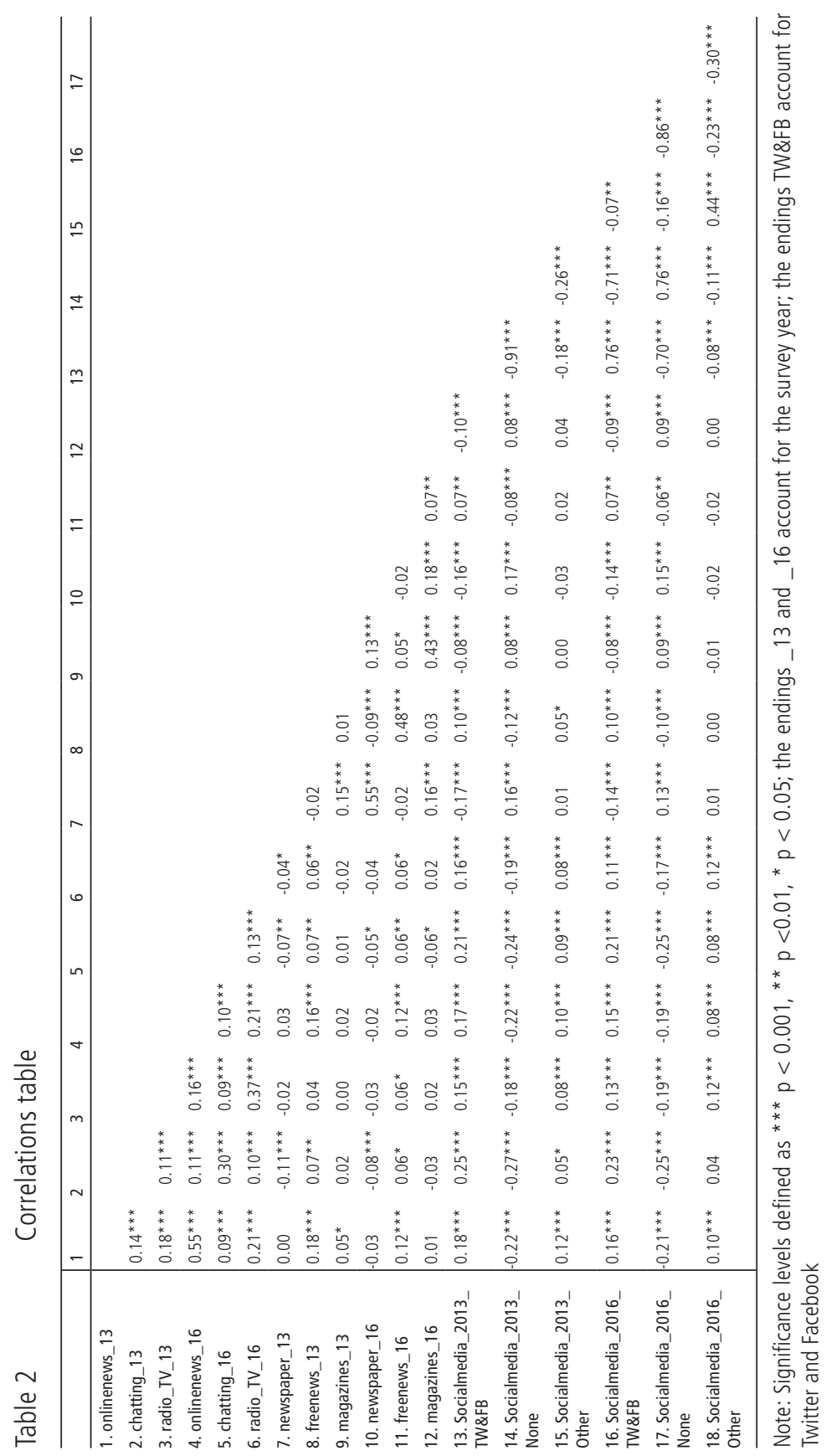


Table 3 Descriptive statistics for the supplementary variables

\begin{tabular}{|c|c|c|c|}
\hline \multirow[b]{2}{*}{ Political self-positioning (politor) } & \multirow{2}{*}{$\begin{array}{l}\text { Modalities } \\
\text { extreme-left stable (ext.-left) }\end{array}$} & \multicolumn{2}{|c|}{ Count $(\%)$} \\
\hline & & 55 & (3) \\
\hline & left stable (left) & 361 & (18) \\
\hline & centre stable (centre) & 923 & (47) \\
\hline & right stable (right) & 282 & (14) \\
\hline & extreme-right stable (ext.-right) & 43 & (2) \\
\hline & moderate change toward left (left+) & 167 & (8) \\
\hline & moderate change toward right (right+) & 139 & (7) \\
\hline \multirow[t]{7}{*}{ Political interest (polint) } & very low stable (very low) & 52 & (3) \\
\hline & low stable (low) & 111 & (6) \\
\hline & middle stable (middle) & 441 & (22) \\
\hline & high stable (high) & 656 & (33) \\
\hline & very high stable (very high) & 243 & (12) \\
\hline & moderate decrease (less-) & 198 & (10) \\
\hline & moderate increase (more+) & 269 & (14) \\
\hline \multirow[t]{6}{*}{ Age cohorts (cohort) } & $<1942$ & 203 & (10) \\
\hline & 1943-1952 & 360 & (18) \\
\hline & 1953-1962 & 532 & (27) \\
\hline & 1963-1972 & 453 & (23) \\
\hline & 1973-1982 & 249 & (13) \\
\hline & 1983-1999 & 173 & (9) \\
\hline \multirow[t]{2}{*}{ Occupation (prof.status) } & active & 1316 & (67) \\
\hline & non active & 654 & (33) \\
\hline \multirow[t]{2}{*}{ Gender (SEX) } & $\operatorname{man}$ & 848 & (43) \\
\hline & woman & 1122 & (57) \\
\hline \multirow[t]{5}{*}{ Type of commune (COM2) } & tourist and wealthy town & 175 & (9) \\
\hline & centres & 576 & (29) \\
\hline & urban towns & 808 & (41) \\
\hline & Industrial and tertiary sector towns & 130 & (7) \\
\hline & rural towns & 281 & (14) \\
\hline \multirow[t]{4}{*}{ Education (EDUCATr) } & compulsory & 62 & (3) \\
\hline & general & 204 & (10) \\
\hline & tertiary & 949 & (48) \\
\hline & vocational & 755 & (38) \\
\hline \multirow[t]{7}{*}{ Regions (REGION) } & Central Switzerland & 205 & (10) \\
\hline & East Switzerland & 203 & (10) \\
\hline & Lake Geneva & 346 & (18) \\
\hline & Middleland & 498 & (25) \\
\hline & Northwest Switzerland & 300 & (15) \\
\hline & Ticino & 52 & (3) \\
\hline & Zurich & 366 & $(19 \%)$ \\
\hline
\end{tabular}


status, $67 \%$ of the sample were active and $33 \%$ were inactive. With respect to education, most of the included individuals have a tertiary education diploma (48\%), followed by vocational school (38\%), general (10\%), and compulsory school (3\%). Furthermore, women are more represented than men (57\% versus $43 \%$ ). Finally, respondents living in urban municipalities $(41 \%)$ were more represented than respondents living in centres (29\%), in rural municipalities (14\%), in tourist and wealthy municipalities $(9 \%)$ and in industrial and tertiary sector municipalities (7\%). Concerning the regions, people in our sample came mostly from the Middleland (25\%) and from the region of the Lake of Geneva (18\%), while very few live in Ticino (3\%).

\subsection{Illustrating media consumption patterns with individuals and contextual factors}

By retaining more than $80 \%$ of the inertia, two axes contributed to structuring the map of the media consumption patterns. The variance rate of the first axis was larger than that of the second axis (67\% vs. $17 \%$ ), which indicates a particularly strong opposition in space along the first axis compared to the second.

Social media in 2013 and 2016 made above-average contributions to the first axis. On the negative side of the plot (left side), we find the absence of social media use and the absence of reading online news in 2013 and 2016. In contrast (right of the axis in the graph), we find the use of Facebook and Twitter in 2013 and 2016, frequent chatting and frequent listening to the radio or watching TV online in 2013 and 2016. We also find the absence of consulting newspapers and online news. Thus, we argue that the first axis refers to a main cleavage between the reliance on social media associated with frequent online behaviours, such as chatting and listening to the radio or watching TV online, and the absence of use of social media and the absence of online news consumption.

The second axis was defined mainly by the different categories of newspaper and magazine consumption (in 2013 and 2016). We find in the negative coordinates (bottom of the axis in the graph) the frequent reading of magazines, as well as the frequent consumption of newspapers. In the positive coordinates (top of the axis in the graph), we find the absence of reading online news, offline newspapers and magazines. Thus, this axis refers to the main cleavage between the consultation of news and the absence of reading offline or online media content.

Some interesting trends can be highlighted by comparing the distances between media consumption measured in 2013 and 2016. First, whereas frequent consumption of offline and online news are located closer together on the map (lower-right quadrant), the absence of consumption of these media is situated further apart (upper-left quadrant). Second, the consumption of every media type included in the analysis has not changed much between 2013 and 2016 (as shown with the descriptive statistics in Table 1). Third, the reliance of social media such as Facebook and Twitter (situated in the upper-right quadrant) follows a different logic 
Figure $1 \quad$ Map of active and supplementary modalities

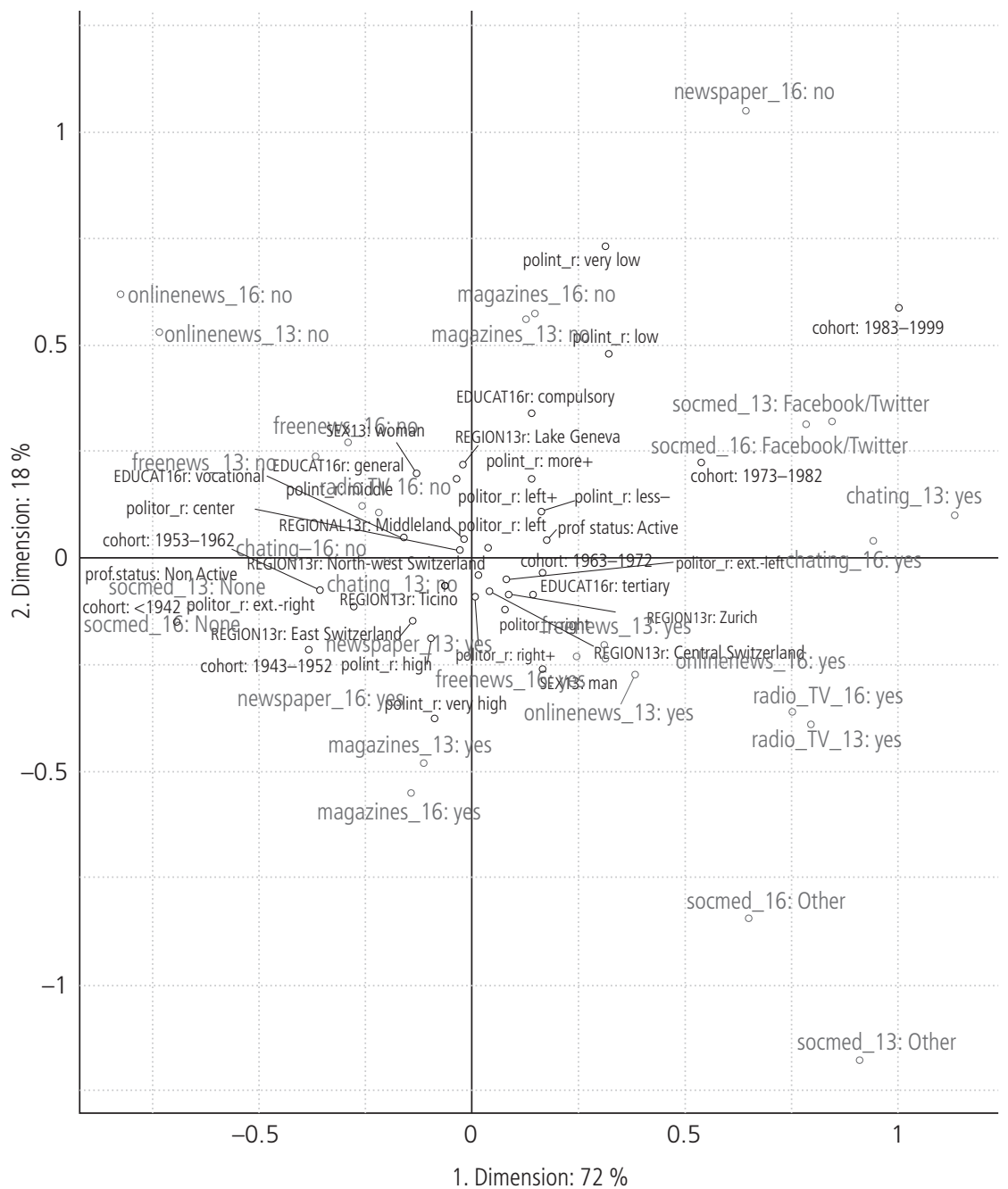

Note: The endings_13 and_16 account for the survey year; active variables are in grey and supplementary variables in black; $\mathrm{N}=1970$

than reliance on other social media such as LinkedIn, Xing, MySpace and Google+ (situated in the lower-right quadrant).

To better understand possible age differences in the use of media, MCA was also performed separately by three groups of cohorts (1983-1999 for the younger group, 1973-1982 and 1963-1972 for the intermediate group, and 1953-1962, 


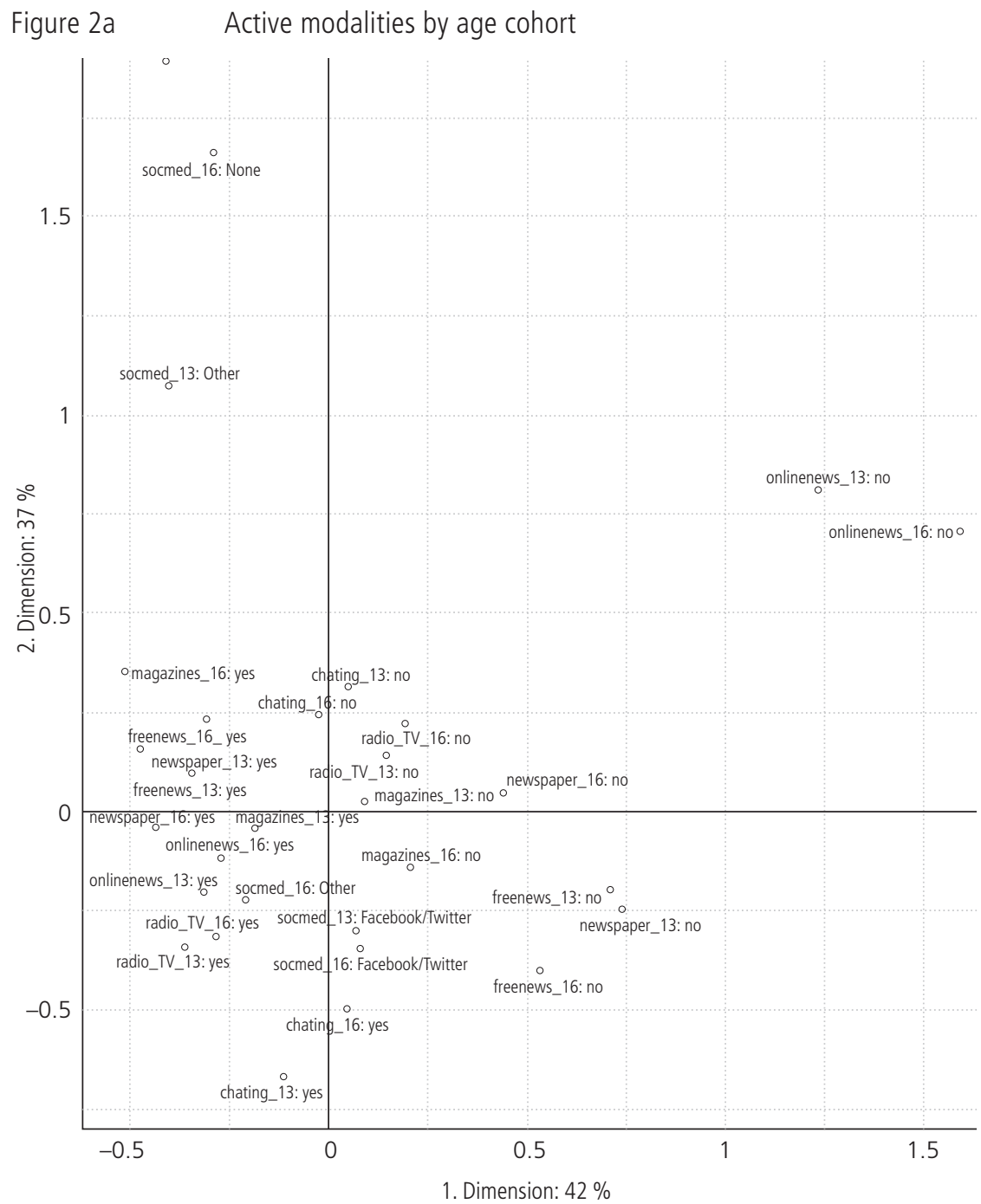

Note: Variable abbreviations are the same as in Figure 1; the number of individuals equals 173 in the young cohort, 702 in the intermediate cohort, and 1095 in the older cohort.

1943-1952 and before 1942 for the older group). Figure 2 shows that all of the variables had similar reciprocal relationships, and the axes of the overall model were replicated. The differences among the younger cohort were mostly prompted by not using social media and online news and by using the Internet for chatting or using social media other than Facebook and Twitter. However, these differences 
Figure $2 \mathrm{~b} \quad$ Active modalities by age cohort

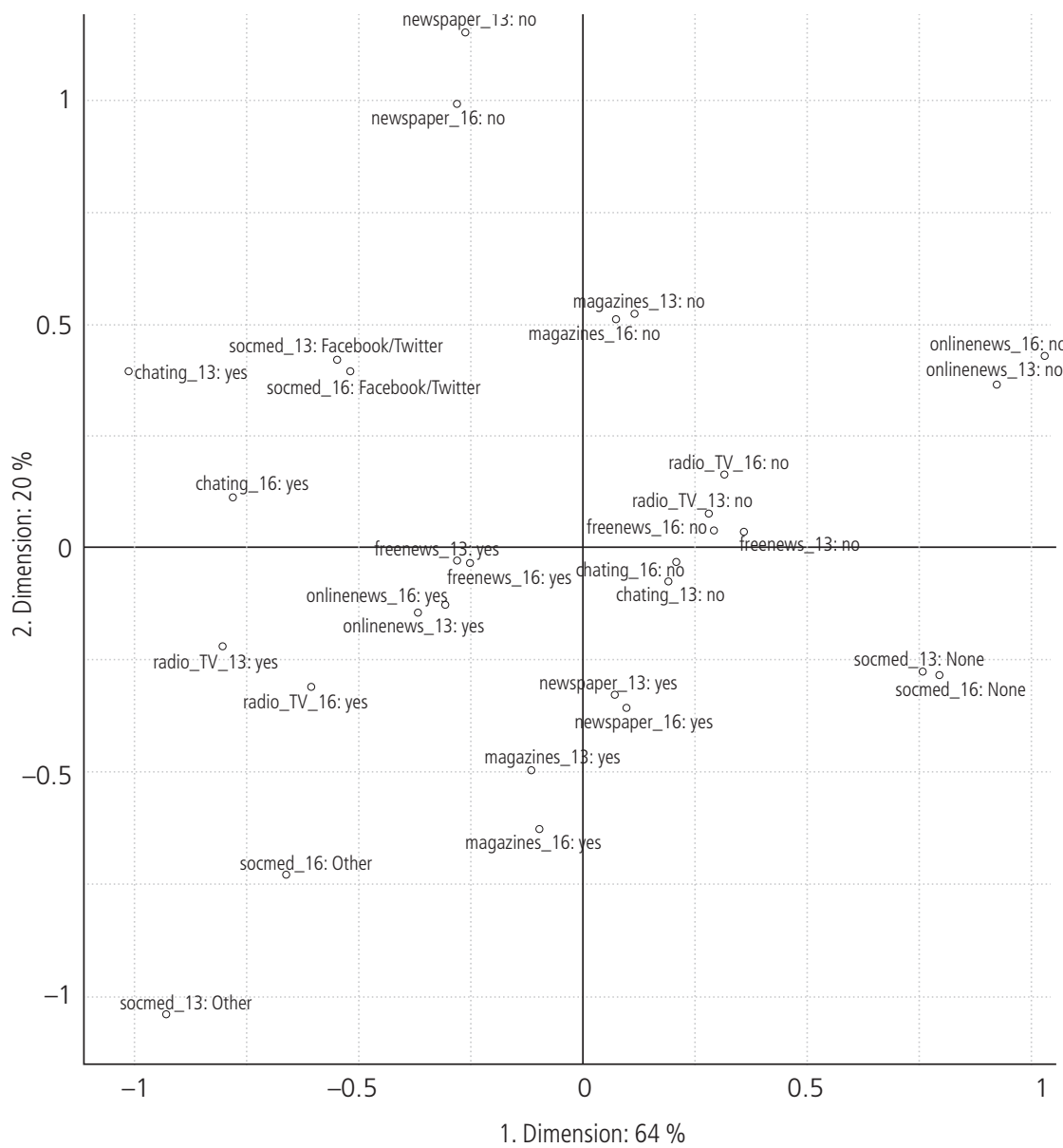

Note: Variable abbreviations are the same as in Figure 1; the number of individuals equals 173 in the young cohort, 702 in the intermediate cohort, and 1095 in the older cohort.

became less accentuated in 2016, showing a more homogenous consumption of the Internet and social media. A similar trend is observable for the other two cohorts. Among groups of cohorts, the use of offline media was also quite diverse, and more polarized consumption types were observed. 
Figure $2 \mathrm{c} \quad$ Active modalities by age cohort

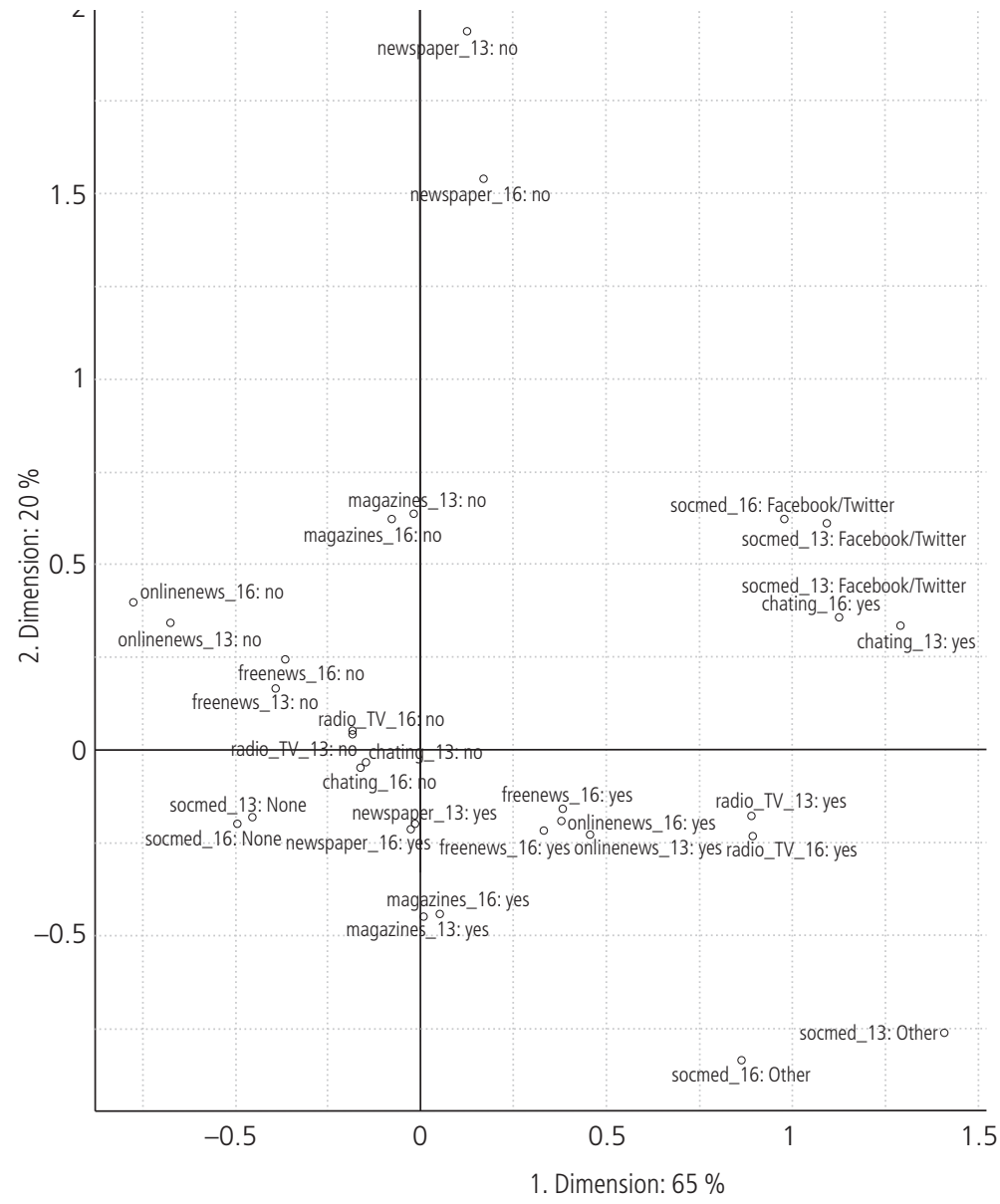

Note: Variable abbreviations are the same as in Figure 1; the number of individuals equals 173 in the young cohort, 702 in the intermediate cohort, and 1095 in the older cohort.

\subsection{Explaining different consumption profiles}

Figure 1 shows the supplementary variables projected on the media consumption landscape (labels in black on the figure). Overall, there was little difference between political self-positioning and types of municipalities. The age cohorts were structured 
along the first axis, which summarizes the opposition between the reliance on or absence of reliance on social media. Younger respondents (see upper-right quadrant) were associated with reliance on social media, frequent chatting, and the absence of both online and offline news and magazine consultation, while older cohorts (see lower-left quadrant) were associated with the absence of social media usage, as well as the frequent consumption of daily news and magazines. With respect to the second axis, political interest and gender could explain the repartition of the active modalities. Respondents expressing no change in their level of political interest and who were highly interested in politics were situated in the upper-right quadrant. Gender also showed differences: women had positive values on the second axis, and men had negative values on the second axis.

Figure 1 also shows which of the supplementary categories are most important when interpreting the formation of the dimensions. The different age cohorts were structured mainly along the first dimension, whereas the changing level of political interest, as well as gender, were important variables when interpreting the second dimension.

To test the repartition of individuals, cluster analysis can be used to look for groups (or clusters) that bring together respondents sharing similar media consumption patterns. This procedure maximizes the homogeneity of clusters so that respondents in each cluster are most similar to one another and most of the differences are between clusters. Over several tested models, the best fit (i. e., best Duda-Hart, PseudoT2, and Beale indexes) was given by two clusters. The first cluster (named new media consumers) is characterized mainly by social media use, chatting, watching TV or listening to the radio online, and free news consumption, whereas the second cluster (news consumers) is defined mainly by information consumption practices through the use of traditional media outlets, such as offline newspapers and magazines, as well as online media outlets. In a final step, the two clusters were profiled using the supplementary variables not used to identify the clusters by means of a logistic regression (Table 4).

The results confirm that younger age cohorts were classified as new media consumers significantly more often than were older cohorts. Men were more likely to be associated with this group of consumers than women. Moreover, urban towns were more likely to be represented in the new media cluster than rural towns. People with high and middle levels of political interest are also more likely to be associated with news consumption than people with very low levels of political interest. Political orientation showed no significant results but tends to inform the polarization behaviour of those with rightist political inclinations, as we observed that people with extreme-right self-positioning tend to rely less on new media than left-leaning people. Finally, people living in East Switzerland are less likely to rely on new media than people living in the region of Zurich. 
Table $4 \quad$ Logistic regression on the new media consumers cluster (coded as 0 ) and the news consumers cluster (coded as 1)

\begin{tabular}{|c|c|c|c|}
\hline & & $\beta$ (SE) & $\mathrm{p}$ \\
\hline (Intercept) & & $-0.61(0.67)$ & 0.36 \\
\hline \multirow{6}{*}{$\begin{array}{l}\text { Political self-positioning (politor):: reference } \\
\text { "left" }\end{array}$} & ext.-left & $-0.02(0.39)$ & 0.96 \\
\hline & centre & $0.01(0.18)$ & 0.94 \\
\hline & ext.-right & $0.89(0.54)$ & 0.09 \\
\hline & left+ & $0.05(0.28)$ & 0.85 \\
\hline & right & $-0.07(0.23)$ & 0.77 \\
\hline & right+ & $0.17(0.31)$ & 0.59 \\
\hline \multirow[t]{6}{*}{ Political interest (polint):: reference "very low" } & high & $0.92(0.45)$ & $0.04^{*}$ \\
\hline & less- & $0.18(0.48)$ & 0.71 \\
\hline & low & $0.26(0.51)$ & 0.61 \\
\hline & middle & $0.83(0.45)$ & $0.07 a$ \\
\hline & more+ & $0.5(0.47)$ & 0.28 \\
\hline & very high & $0.54(0.48)$ & 0.26 \\
\hline \multirow[t]{5}{*}{ Age cohorts (cohort):: reference "<1942" } & 1943-1952 & $-1.13(0.25)$ & $<.01^{* *}$ \\
\hline & 1953-1962 & $-1.63(0.29)$ & $<.01$ ** \\
\hline & 1963-1972 & $-2.46(0.31)$ & $<.01$ ** \\
\hline & 1973-1982 & $-3.19(0.35)$ & $<.01^{* *}$ \\
\hline & 1983-1999 & $-5.77(0.77)$ & $<.01$ ** \\
\hline Gender (SEX):: reference "man" & woman & $0.91(0.14)$ & $<.01$ ** \\
\hline \multirow[t]{4}{*}{$\begin{array}{l}\text { Type of commune (COM2):: reference "urban } \\
\text { towns" }\end{array}$} & $\begin{array}{r}\text { tourist and wealthy } \\
\text { town }\end{array}$ & $0.07(0.23)$ & 0.76 \\
\hline & centres & $-0.21(0.17)$ & 0.21 \\
\hline & $\begin{array}{r}\text { industrial and tertiary } \\
\text { sector towns }\end{array}$ & $0.33(0.27)$ & 0.23 \\
\hline & rural towns & $-0.37(0.21)$ & $0.08 \mathrm{a}$ \\
\hline \multirow[t]{3}{*}{ Education (EDUCATr):: reference "tertiary" } & compulsory & $-0.67(0.41)$ & 0.10 \\
\hline & general & $0.37(0.22)$ & 0.09 \\
\hline & vocational & $0.11(0.15)$ & 0.48 \\
\hline \multirow[t]{6}{*}{ Regions (REGION):: reference "Zurich" } & Central Switzerland & $0.23(0.27)$ & 0.38 \\
\hline & East Switzerland & $0.6(0.26)$ & $0.02^{*}$ \\
\hline & Lake Geneva & $-0.12(0.22)$ & 0.59 \\
\hline & Middleland & $0.18(0.2)$ & 0.36 \\
\hline & Northwest Switzerland & $0.12(0.22)$ & 0.60 \\
\hline & Ticino & $0.14(0.44)$ & 0.75 \\
\hline Occupation (prof.status):: reference "inactive" & active & $-0.05(0.2)$ & 0.79 \\
\hline
\end{tabular}

Note: Significance levels defined as ${ }^{* *} p<0.01,{ }^{*}<0.05$, a $p<0.08 ; N=1416$. 


\section{$4 \quad$ Discussion and concluding remarks}

The findings of the present study relied on an innovative way to exploit MCA by adding a temporal variation to the map. This use of MCA was first proposed by Mercklé (2017), Rossier (2018), and Rossier and Fillieule (2019), and some aspects of it still need to be deepened. However, it is a particularly promising technique and allowed us to highlight consumption patterns from a temporal perspective while seeking to explain them through individual and contextual factors. If, on the one hand, this approach has some limitations, such as the absence of clear-cut statistical tests, on the other hand, it allowed us to explore the multivariate and non-linear relationship between the study variables. Another limitation of this study was that it relied on a time window of only three years (2013 and 2016), which might be too narrow to observe radical changes in behaviour, consumption profiles and opinions. Our results showed that changes in both media usage and the covariate variables, particularly political interest and political positioning, have nevertheless occurred. Future studies relying on data from the SHP 2019 could test the hypothesis of opinion polarisation.

Our first research question asked whether it is possible to observe a digital shift in the analysis of media-use practices or, in other words, if it is possible to account for a digital-oriented versus a paper-oriented media consumption space. This distinction emerged clearly from the map of media consumption practices, showing a contrast between online and offline media consumption. However, the MCA found that more than one dimension explains the difference in consumption styles. This finding implies that the Swiss media space cannot be interpreted solely in a dichotomous offline-online view. Instead, it seems that social media, which offer the possibility for users to generate content and gain information, goes hand in hand with the consumption of other online news sources and offline media sources, mainly free news.

The relationship between using social media and reading only free or lowerquality sources might be particularly problematic in the context of direct democracy because information plays a vital role in guaranteeing informed opinion and votes. Indeed, a narrow consumption of news, whether online or offline, was associated with low political interest. Our second research question, which addressed what individual factors best explain the formation of this media space, shed some more light in this direction. Our results show that the increase in online media is most common among younger cohorts. The age cohorts were structured along the first axis, which summarized the opposition between the reliance or absence of reliance on social media: younger respondents more often relied on social media, reported frequent chatting, and reported the absence of both online and offline news and magazine consultation, while older respondents were characterized by an absence of social media usage, as well as frequent daily news and magazine consultation. Our 
findings therefore show that younger cohorts use social media in a homogenous way, giving higher preference not only to interactive media such as social media and chat services but also to online and free news. With respect to the second axis, which summarizes the opposition between the consultation of and absence of reading offline or online news content, political interest, gender, and, to some extent, political orientation, it illustrates the repartition of media consumption patterns.

The cluster analysis also showed that media consumption is cumulative: People with the habit of seeking information use different types of media at the same time. In line with research on interactive media usage (Opgenhaffen and d'Haenens 2011; Tran 2015), this audience might therefore develop expertise in using media, maximizing the benefits of online support and possibly contrasting the negative side effects of social media. This explanation complements the generational divide hypothesis by emphasizing the skill divide hypothesis. Indeed, as Genner (2017) suggests, the ways we consume information may well transcend questions of age, and the growing online news ecosystem is likely to increase the divide between individuals with versus those without the needed skills to sort through the available news and information.

To conclude, we would like to stress that the change in media usage habits is not necessarily negative for democracy. It can indeed demonopolize the news industry, creating grassroots and alternative sources of information. For instance, the use of social media in collective action and mass protest, such as the wave of protest that impacted Chile in 2019, has allowed activists to draw attention to (alleged) human rights violations committed by the police that had been neglected by official news. However, to maximize these benefits, a new culture of media consumption should be created. Users/readers should be encouraged to use multiple media sources and be aware of the way automated algorithms of news selection work in order to contrast the hidden risks of new media. An informed use of new media could thus represent a resource for, instead of a risk to, direct democracy.

\section{$5 \quad$ References}

Alejandro, Jennifer. 2010. Journalism in the Age of Social Media. Reuters Institute Fellowship Paper, 5: 1-47.

Annales. 2017. Qualité des médias. Zürich: Forschungsinstitut Öffentlichkeit und Gesellschaft, https:// www.foeg.uzh.ch/dam/jcr:15172213-4895-42c5-aaf9-850d9a412d9c/Broschur_Jahrbuch_foeg_ franz_2017_ohne_Sperrvermerk.pdf (18.06.2019).

Ball-Rokeach, Sandra J., et Melvin L. DeFleur. 1976. A Dependency Model of Mass-media Effects. Communication research, 3(1): 3-21.

Bennett, W. Lance. 1993. Constructing Publics and Their Opinions. Political Communication, 10: 101-120.

Colleoni, Elanor, Alessandro Rozza, and Adam Arvidsson. 2014. Echo Chamber or Public Sphere? Predicting Political Orientation and Measuring Political Homophily in Twitter Using Big Data. Journal of Communication 64 (2): 317-32. 
Eveland, William P., Krisztina Marton, and Mihye Seo. 2004. Moving Beyond 'Just the Facts': The Influence of Online News on the Content and Structure of Public Affairs Knowledge. Communication Research 31(1): 82-108.

Flaxman, Seth, Sharad Goel, and Justin M. Rao. 2016. Filter Bubbles, Echo Chambers, and Online News Consumption. Public Opinion Quarterly 80 (S1): 298-320.

Fög. 2016. Qualität der Medien: Hauptbefunde Jahrbuch 2016. https://www.qualitaet-der-medien.ch/ hauptbefunde (01.03.2019)

Fög. 2017. Qualität der Medien: Hauptbefunde Jahrbuch 2017. https://www.qualitaet-der-medien.ch/ hauptbefunde (01.03.2019)

Fög. 2018. Qualität der Medien: Hauptbefunde Jahrbuch 2018. https://www.qualitaet-der-medien.ch/ hauptbefunde (01.03.2019)

Gamson, William A., and Andre Modigliani. 1989. Media Discourse and Public Opinion on Nuclear Power: A Constructionist Approach. American Journal of Sociology, 95(1): 1-37.

Genner, Sarah. 2017. Does age determine media habits in Switzerland? Retrieved from https://www. swissinfo.ch/eng/youth-and-media_does-age-determine-media-habits-in-switzerland--/43551692 (10.10.2020).

Gorodnichenko, Yuriy, Tho Pham, and Oleksandr Talavera. 2018. Social Media, Sentiment and Public Opinions: Evidence from\# Brexit and\# USElection. Working Paper No. w24631. University of Swansea, National Bureau of Economic Research. https://econpapers.repec.org/paper/swnwpaper/2018-01.htm (18.06.2019).

Hart, Roderick P. 1999. Seducing America: How Television Charms the Modern Voter. Sage.

Häuptli, Andrea, Schranz, Mario, and Jörg Schneider. 2017. Situation actuelle et perspectives pour le paysage médiatique dans les régions de montagne. Fribourg: Journée d'étude SAB. http://www. sab.ch/fileadmin/user_upload/customers/sab/Tagungen/2017/Fribourg/01_Andrea_GeneralPraesentation_BergregionenTagung_10-11-2017__fr.pdf (18.06.2019).

Hedman, Ulrika, and Monika Djerf-Pierre. 2013. The Social Journalist: Embracing the Social Media Life or Creating a New Digital Divide? Digital Journalism, 1(3): 368-385.

Jiang, Tonglin, Yubo Hou, and Qi Wang. 2016. Does Micro-blogging Make Us "shallow"? Sharing Information Online Interferes with Information Comprehension. Computers in Human Behavior, 59: $210-214$.

Keane, John. 1991. Democracy and the Media. International Social Science Journal, 129 (s1): 523-540.

Kertzer, J. D., \& Zeitzoff, T. (2017). A bottom-up theory of public opinion about foreign policy. American Journal of Political Science, 61(3): 543-558.

Latzer, Michael. 08.11.2017. Strong Digital Well-Being in Switzerland. University of Zürich,https:// www.media.uzh.ch/en/Press-Releases/2017/Digital-Well-Being-.html (18.06.2019).

Merklé, Pierre. 2017. Une traversé de l'adolescence. Culture, classes, réseaux. Thesis, Institut d'études politiques, Université de Paris, FR.

Neisser, Ulric. 1976. Cognition and reality: Principles and Implications of Cognitive Psychology. New York: WH Freeman/Times Books/Henry Holt and Co.

Opgenhaffen, Michaèl, and Leen d'Haenens. 2011. The Impact of Online News Features on Learning From News. A Knowledge Experiment. International Journal of Internet Science, 6(1): 8-28.

Pariser, Eli. 2011. The Filter Bubble: What the Internet Is Hiding from You. London: Penguin UK.

Price, Vincent. 1988. On the Public Aspects Of Opinion: Linking Levels of Analysis in Public Opinion Research. Communication Research, 15(6): 659-679.

Quattrociocchi, Walter, Antonio Scala, and Cass R. Sunstein. 2016. Echo Chambers on Facebook. SSRN Scholarly Paper ID 2795110. Rochester, NY: Social Science Research Network. https://papers. ssrn.com/abstract=2795110 (18.06.2019). 
Ratkiewicz, Jacob, Michael Conover, Mark Meiss, Bruno Gonçalves, Snehal Patil, Alessandro Flammini, and Filippo Menczer. 2011. Truthy: Mapping the Spread of Astroturf in Microblog Streams. Proceedings of the $20^{\text {th }}$ international conference companion on World wide web, 249-252. ACM.

Reuters. 2016. Digital News Report. Switzerland. http://www.digitalnewsreport.org/survey/2016/ switzerland-2016/ (18.06.2019).

Reuters. 2018. Digital News Report. Switzerland. http://www.digitalnewsreport.org/survey/2018/ switzerland-2018/ (18.06.2019).

Rossier, Thierry. 2018. Construire au moyen d'une analyse des correspondances multiples dynamique l'espace des devenirs soixante-huitards. Pp. 1087-1106 in Changer le monde, changer sa vie, edited by Olivier Fillieule, Isabelle Sommier, Camille Masclet, and Thomas Hirsch. Paris: Acte sud.

Rossier, Thierry, and Olivier Fillieule. 2019. Devenir(s) militants: Proposition de méthode pour une exploration des conséquences biographiques de l'engagement des soixante-huitards. Revue Française de Science Politique, 69(4): 631-683.

Street, John. 2005. Politics Lost, Politics Transformed, Politics Colonised? Theories of the Impact of Mass Media. Political Studies Review, 3(1): 17-33.

Swiss Federal Council. 2017. Un cadre juridique pour les médias sociaux: nouvel état des lieux. Bern, https://www.bakom.admin.ch/dam/bakom/fr/dokumente/informationsgesellschaft/social_media/ social\%20media\%20bericht.pdf.download.pdf/rapport-media-sociaux-2017-FR.pdf (18.06.2019).

Tran, Hai L. 2015. More or less? Multimedia Effects on Perceptions of News Websites. Electronic News, 9(1): 51-67.

Willemin, Nicolas. 2018. Médias Suisses, Le Virage Numérique. Lausanne: Livreo-Alphil.

Woolley, Samuel C. 2016. Automating Power: Social Bot Interference in Global Politics. First Monday, 21(4).

\section{Appendix}

Table A1 Contribution of variables and modalities to the formation of MCA axes

\begin{tabular}{lrccr}
\hline & Modalities & Dimension 1 & Dimension 2 & Freqency \\
\hline Chatting 2013 (chatting_13) & no & 1.1 & 0 & 1692 \\
& yes & 6.5 & 0.1 & 278 \\
Chatting 2016 (chatting_16) & Total & 7.6 & 0.1 & 1970 \\
& no & 1.1 & 0 & 1629 \\
Dailynews 2013 (dailynews_13) & yes & 5.5 & 0 & 341 \\
& Total & 6.6 & 0 & 1970 \\
& no & 2.7 & 14.5 & 327 \\
Dailynews 2016 (dailynews_16) & yes & 0.5 & 2.9 & 1643 \\
& Total & 3.2 & 17.4 & 1970 \\
& no & 3 & 11.9 & 407 \\
& yes & 0.8 & 3.1 & 1563 \\
& Total & 3.8 & 15 & 1970 \\
\hline
\end{tabular}


Continuation of table $A 1$.

\begin{tabular}{|c|c|c|c|c|}
\hline & Modalities & Dimension 1 & Dimension 2 & Freqency \\
\hline \multirow[t]{3}{*}{ Freenews 2013 (freenews_13) } & no & 2.2 & 1.4 & 907 \\
\hline & yes & 1.9 & 1.2 & 1063 \\
\hline & Total & 4.1 & 2.6 & 1970 \\
\hline \multirow[t]{3}{*}{ Freenews 2016 (freenews_16) } & no & 1.4 & 1.8 & 911 \\
\hline & yes & 1.2 & 1.5 & 1059 \\
\hline & Total & 2.6 & 3.3 & 1970 \\
\hline \multirow[t]{3}{*}{ Magazine 2013 (magazine_13) } & no & 0.3 & 7.6 & 912 \\
\hline & yes & 0.2 & 6.5 & 1058 \\
\hline & Total & 0.5 & 14.1 & 1970 \\
\hline \multirow[t]{3}{*}{ Magazine 2016 (magazine_16) } & no & 0.4 & 8.4 & 968 \\
\hline & yes & 0.4 & 8.1 & 1002 \\
\hline & Total & 0.8 & 16.5 & 1970 \\
\hline \multirow[t]{3}{*}{ Onlinenews 2013 (onlinenews_13) } & no & 6.6 & 5 & 677 \\
\hline & yes & 3.5 & 2.6 & 1293 \\
\hline & Total & 10.1 & 7.6 & 1970 \\
\hline \multirow[t]{3}{*}{ Onlinenews 2016 (onlinenews_16) } & no & 6.7 & 5.6 & 547 \\
\hline & yes & 2.6 & 2.1 & 1423 \\
\hline & Total & 9.3 & 7.7 & 1970 \\
\hline \multirow[t]{3}{*}{ Radio and TV 2013 (radio_TV_13) } & no & 1.3 & 0.5 & 1550 \\
\hline & yes & 4.8 & 1.7 & 420 \\
\hline & Total & 6.1 & 2.2 & 1970 \\
\hline \multirow[t]{3}{*}{ Radio and TV 2016 (radio_TV_16) } & no & 1.7 & 0.6 & 1471 \\
\hline & yes & 5.1 & 1.7 & 499 \\
\hline & Total & 6.8 & 2.3 & 1970 \\
\hline \multirow[t]{4}{*}{ Social media 2013 (Socialmedia_2013) } & $\begin{array}{r}\text { Facebook/ } \\
\text { Twitter }\end{array}$ & 9.8 & 2 & 763 \\
\hline & None & 8.7 & 0.4 & 1112 \\
\hline & Other & 1.4 & 3.5 & 95 \\
\hline & Total & 19.9 & 5.9 & 1970 \\
\hline \multirow[t]{4}{*}{ Social media 2016 (Socialmedia_2016) } & $\begin{array}{r}\text { Facebook/ } \\
\text { Twitter }\end{array}$ & 8.8 & 2 & 787 \\
\hline & None & 8.8 & 0.4 & 1039 \\
\hline & Other & 1.1 & 2.7 & 144 \\
\hline & Total & 18.7 & 5.1 & 1970 \\
\hline
\end{tabular}

Note: Significance levels defined as ${ }^{* *} p<0.01,{ }^{*}<0.05$, a $p<0.08 ; N=1416$. 